\title{
Исследование влияния обработки поверхности Si-подложек на морфологию слоев GaP, полученных методом плазмохимического атомно-слоевого осаждения
}

\author{
(C) А.В. варов $^{1}$, В.А. Шаров ${ }^{1,2}$, Д.А. Кудряшов ${ }^{1}$, А.С. Гудовских ${ }^{1,3}$ \\ ${ }^{1}$ Санкт-Петербургский Академический университет им. Ж.И. Алфёрова Российской академии наук, \\ 194021 Санкт-Петербург, Россия \\ ${ }^{2}$ Физико-технический институт им. А.Ф. Иоффе Российской академии наук, \\ 194021 Санкт-Петербург, Россия \\ ${ }^{3}$ Санкт-Петербургский государственный электротехнический университет „ЛЭТИ“ им. В.И. Ульянова (Ленина), \\ 197376 Санкт-Петербург, Россия \\ E-mail: lumenlight@mail.ru
}

Поступила в Редакцию 28 сентября 2021 г.

В окончательной редакции 10 октября 2021 г.

Принята к публикации 10 октября 2021 г.

\begin{abstract}
Проведены исследования по атомно-слоевому осаждению слоев $\mathrm{GaP}$ на подложки $\mathrm{Si}$ с различной ориентацией и с различной предварительной обработкой поверхности. Осаждение GaP проводилось методом плазмохимического атомно-слоевого осаждения с использованием in situ обработки в плазме аргона. Показано, что на начальном этапе роста слоев GaP на Si-подложках, точно ориентированных (100) и с разориентацией, происходит двумерный рост как после химической, так и плазменной обработки поверхности. При росте на подложках (111) после плазменной обработки поверхности наблюдается переход в трехмерный рост, при котором размер островков достигает 30-40 нм. Наименьшая среднеквадратичная шероховатость поверхности растущих слоев $\mathrm{GaP}$ (<0.1 нм) была достигнута для подложек (100) с разориентацией $4^{\circ}$. Слои $\mathrm{GaP}$, выращенные на точно ориентированных (100) подложках, обладали шероховатостью $\sim 0.1$ нм, а на подложках с ориентацией $(111)-0.12$ нм. Было обнаружено, что обработка поверхности Si-подложек с ориентацией (100) в водородной плазме приводит к незначительному увеличению шероховатости поверхности растущих слоев $\mathrm{GaP}(0.12-0.14$ нм), что связывается с эффектом неоднородного травления кремния в водородной плазме. При обработке поверхности (100) кремния в плазме аргона шероховатость поверхности существенно не меняется по сравнению с химической обработкой поверхности. На поверхности подложек с предварительным осаждением эпитаксиального слоя $\mathrm{Si}$ толщиной 4 нм морфология слоев $\mathrm{GaP}$ аналогична ситуации с применением водородной плазмы.
\end{abstract}

Ключевые слова: плазмохимическое осаждение, атомно-слоевое осаждение, кремний, фосфид галлия.

DOI: 10.21883/FTP.2022.02.51964.9748

\section{1. Введение}

Развитие солнечной энергетики требует постоянного совершенствования характеристик солнечных элементов (СЭ), важнейшим параметром которых является эффективность преобразования солнечной энергии (кпд). Одним из наиболее успешных способов повышения кпд солнечных элементов является использование гетероструктур, в которых используется гетеропереход между широкозонным эмиттером и поглощающим материалом. Примером успешного применения этого подхода являлось интенсивное развитие СЭ на основе гетероперехода $a-\mathrm{Si}: \mathrm{H} / c$-Si. Использование тонкого слоя (< 5 нм) нелегированного аморфного гидрогенизированного кремния $(a-\mathrm{Si}: \mathrm{H})$, покрытого высоколегированным слоем $a-\mathrm{Si}: \mathrm{H}$, позволило достичь близкое к теоретическому пределу значение кпд для СЭ на основе кремния [1]. Нелегированный слой $a$-Si:H обеспечивает необходимую пассивацию поверхности (низкую плотность поверхностных состояний), а легированные слои формируют изгиб зон в $\mathrm{Si}$-подложке. Однако $a-\mathrm{Si}: \mathrm{H}$ является нестабильным при воздействии температур $>300^{\circ} \mathrm{C}$, что накладывает серьезные ограничения на остальные технологические процессы. Также существенным недостатком использования $a-\mathrm{Si}: \mathrm{H}$ в качестве широкозонного эмиттера являются потери на поглощении части спектра солнечного излучения из-за высокого коэффициента поглощения в коротковолновой области спектра.

В последние годы были предприняты попытки по поиску новых более широкозонных материалов для создания эмиттера с низким коэффициентом поглощения, обеспечивающих хорошую пассивацию Si. Были достигнуты обнадеживающие результаты при использовании оксидов переходных металлов и фторидов для создания дырочного и электронного контактов соответственно [2]. Однако для структур на основе этих материалов до сих пор не решена проблема температурной стабильности [3-5]. В связи с этим определенный интерес представляют соединения $\mathrm{A}^{\mathrm{III}} \mathrm{B}^{\mathrm{V}}$, в частности фосфид галлия $(\mathrm{GaP})$. GaP - непрямозонный широкозонный полупроводник с шириной запрещенной зоны 2.26 эВ, что гарантирует низкие потери на поглощение. За счет небольшой 
разницы в значениях постоянной решетки для $\mathrm{GaP}$ и $\mathrm{Si}(0.4 \%)$ возможно достижение низкой концентрации дефектов на границе раздела $\mathrm{GaP} / \mathrm{Si}$. Большой разрыв валентных зон на этой границе $\left(\Delta E_{V}=0.8-0.95\right.$ эВ) $[6,7]$ ограничивает транспорт дырок, генерируемых в $\mathrm{Si}$, что подавляет поверхностную рекомбинацию. С другой стороны, сравнительно малые значения разрыва зон проводимости $\left(\Delta E_{C}=0.2-0.35\right.$ эВ $)$ обеспечивают эффективный транспорт электронов через границу раздела $\mathrm{GaP} / \mathrm{Si}$. Исходя из зонной структуры гетеропереход $\mathrm{GaP} / \mathrm{Si}$ в первую очередь представляет интерес для создания фотоэлектрических преобразователей на основе $\mathrm{Si} p$-типа проводимости $[6,8]$. Следует добавить, что задача по созданию эффективных СЭ на основе $\mathrm{Si} p$-типа попрежнему является актуальной для низкоорбитальных космических приложений из-за их лучшей радиационной стойкости [9].

Однако, когда речь идет об изготовлении СЭ на промышленном уровне, большое значение имеет технология синтеза, которая должна обеспечить, с одной стороны, высокую производительность и возможность проводить процесс при сравнительно низких температурах, a с другой - высокое качество границы раздела. В связи с этим большой потенциальный интерес представляют масштабируемые низкотемпературные технологии формирования тонких слоев, такие как плазмохимическое осаждение (ПХО), атомно-слоевое осаждение (АСО) или их совмещение, позволяющие проводить осаждение на больших площадях.

Ранее был проведен большой объем исследований по росту $\mathrm{GaP}$ на подложках кремния методом плазмохимического АСО [10-12], который показал перспективность данного направления исследований. В частности, был разработан метод плазмохимического АCO с дополнительной промежуточной обработкой в водородной плазме [10], показано влияние плазменной обработки на электрофизические свойства Si-подложки [11]. Также было продемонстрировано успешное легирование $\mathrm{GaP}$ кремнием для получения $n$-типа проводимости [13], что позволяет получить эффективную фотопреобразовательную структуру на $p$-подложке кремния. Кроме того, была продемонстрирована возможность двухмерного эпитаксиального роста GaP на подложках $\mathrm{Si}$ (100) с разориентацией $4^{\circ}$ в направлении [110], используя метод плазмохимического АCO c in situ отжигом в Ar-плазме [14]. Однако по-прежнему требуется дальнейшее исследование механизма роста на начальных этапах. Необходимо определить влияние плазменной обработки, используемой в процессе, на морфологию поверхности растущего слоя. Также требуется проведение исследований влияния ориентации подложек. При создании СЭ на основе $\mathrm{Si}$, как правило, используется текстурированная поверхность, формируемая за счет анизотропного химического травления подложек с ориентацией (100). Текстурированная поверхность $\mathrm{Si}$-пластин представляет собой пирамидки со средним размером 5 мкм с гранями, ориентированными в направлении [111], следовательно, при формировании СЭ рост слоев $\mathrm{GaP}$ должен осуществляться на поверхности (111). Таким образом, исследование начальных этапов плазмохимического АСО слоев $\mathrm{GaP}$ на подложки $\mathrm{Si}$ с различной ориентацией и с различной предварительной обработкой поверхности является актуальной задачей, на решение которой направлена данная работа.

\section{2. Экспериментальная часть}

Была проведена серия экспериментов по атомнослоевому осаждению слоев $\mathrm{GaP}$ на подложки $\mathrm{Si}$ с различной ориентацией и с различной предварительной обработкой поверхности. Осаждение проводилось на точно ориентированные полированные $\mathrm{Si}$-подложки (100) и (111), а также на Si-подложки (100) с разориентацией $4^{\circ}$ в направлении [110]. Для всех типов подложек непосредственно перед началом процесса осаждения проводилось удаление естественного окисла с помощью химической обработки в $10 \%$ растворе $\mathrm{HF} / \mathrm{H}_{2} \mathrm{O}$.

Далее непосредственно после химической обработки подложки помещались в шлюзовую камеру установки плазмохимического осаждения Oxford Plasmalab 100 PECVD. После откачки шлюзовой камеры подложки перемещались в ростовую камеру на предварительно нагретый до температуры $380^{\circ} \mathrm{C}$ подложкодержатель (диаметром 24 см) и выдерживались в течение 30 мин. Перед осаждением слоя $\mathrm{GaP}$ было проведено четыре серии экспериментов: без плазменной обработки, с обработкой в водородной плазме, с обработкой в плазме аргона и с предварительным осаждением тонкого эпитаксиального слоя $\mathrm{Si}$.

Обработка поверхности $\mathrm{Si}$-подложек в плазме чистого водорода происходила при давлении 0.5 Торр, мощности ВЧ (13.56 МГц) разряда 100 Вт в течение 1 мин. Аналогично проводилась обработка поверхности в плазме чистого аргона при давлении 0.5 Торр, мощности 100 ВТ в течение 1 мин. Процесс предварительного осаждения слоя $\mathrm{Si}$ толщиной 4 нм проходил в условиях, обеспечивающих начальный эпитаксиальный рост на поверхности подложек $\mathrm{GaP}$ [15]. Осаждение происходило при отношении потоков силана к водороду $1 / 50$, мощности 100 Вт и давлении 1.9 Торр.

Далее непосредственно после обработки поверхности при температуре $390^{\circ} \mathrm{C}$ проводился процесс плазмохимического атомно-слоевого осаждения в разработанном ранее режиме с использованием in situ обработки в плазме аргона, обеспечивающем эпитаксиальный рост слоя $\mathrm{GaP}[14]$. Для роста слоев $\mathrm{GaP}$ в качестве источника атомов $\mathrm{Ga}$ и $\mathrm{P}$ использовались металлорганическое соединение $\mathrm{Ga}$ - триметилгаллий $\left(\mathrm{TM \Gamma )}\right.$ и фосфин $\left(\mathrm{PH}_{3}\right)$ соответственно. Процесс плазмохимического атомнослоевого осаждения $\mathrm{GaP}$, заключающийся в циклической поочередной подаче триметилгаллия и фосфина в реакционную камеру, проводился при температуре $390^{\circ}$ C. Разложение $\mathrm{PH}_{3}$ происходит в плазме тлеющего 

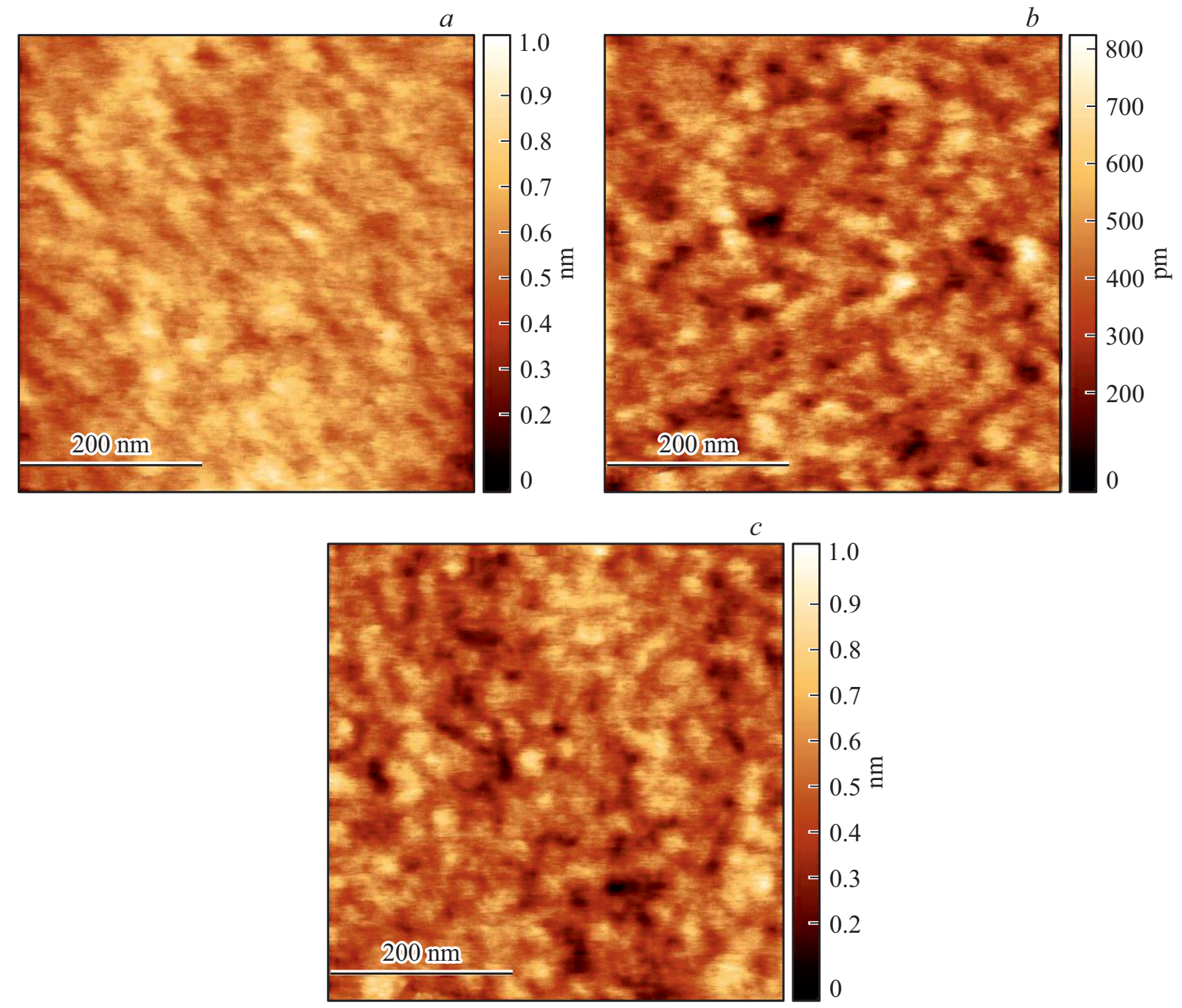

Рис. 1. Морфология поверхности слоя $\mathrm{GaP}$, осажденного без предварительной обработки в плазме на подложки $\mathrm{Si}$ с ориентацией: (100) с разориентацией $4^{\circ}$ в направлении $[110](a),(100)(b),(111)(c)$.

Среднеквадратичная шероховатость для слоев $\mathrm{GaP}$

\begin{tabular}{c|c|c|c|c}
\hline \multirow{2}{*}{ Ориентация подложки } & \multicolumn{4}{|c}{ Обработка поверхности } \\
\cline { 2 - 5 } & $\begin{array}{c}\text { Без обработки, } \\
\text { пм }\end{array}$ & $\begin{array}{c}\text { В плазме } \mathrm{H}_{2} \\
\text { пм }\end{array}$ & $\begin{array}{c}\text { В плазме } \mathrm{Ar}, \\
\text { пм }\end{array}$ & $\begin{array}{c}\text { Тонкий слой } \mathrm{Si}, \\
\text { пм }\end{array}$ \\
\hline$(100) 4^{\circ}$ в направлении $[110]$ & 95 & 147 & 68 & 140 \\
$(100)$ & 97 & 114 & 113 & 114 \\
$(11)$ & 121 & 198 & 206 & 122
\end{tabular}

разряда мощностью 200 Вт и давлении 0.35 Торр. После каждого шага осаждения проводилась продувка камеры с помощью потока Ar. Перед шагом осаждения Ga, осуществляемого за счет термического разложения ТМГ, проводилась активация поверхности растущего слоя с помощью Ar-плазмы мощностью 200 Вт в течение 10 с. Подача ТМГ в камеру осуществлялась с помощью газаносителя - водорода, обеспечивающего концентрацию ТМГ в смеси с водородом на уровне $8 \%$. Для каждой серии процесс осаждения состоял из 20 циклов, чтобы обеспечить результирующую толщину слоя $\mathrm{GaP} \sim 4$ нм.

Для всех структур проводилось исследование морфологии поверхности с помощью атомно-силовой микроскопии (ACM). Измерения были проведены на установке NT-MDT NTegra Aura в полуконтактном режиме, использовались зонды NT-MDT HA_NC с резонансной частотой $\sim 235$ кГц и радиусом закругления острия $<10$ нм. Для всех образцов размер скана составил 


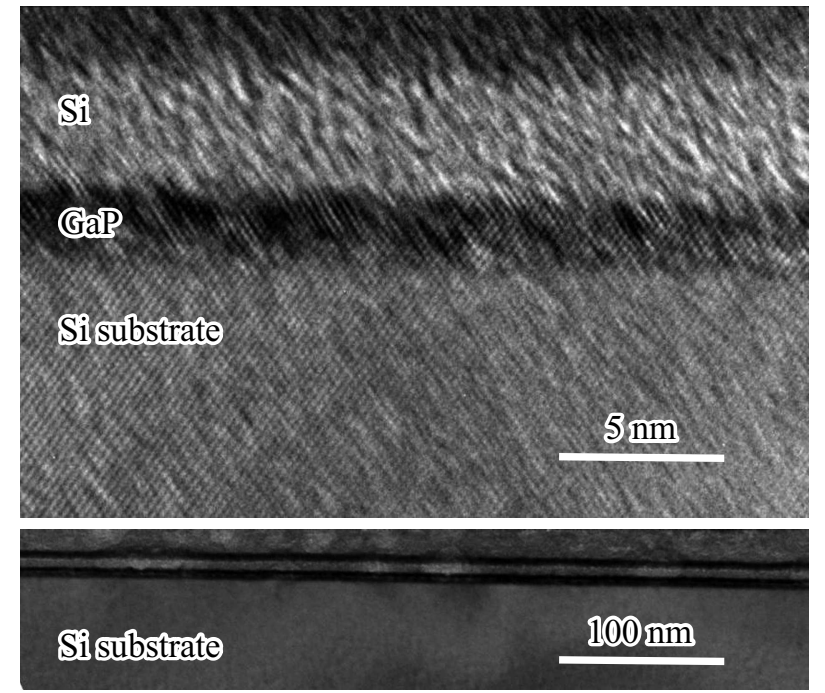

Рис. 2. ПЭМ поперечного сечения $\mathrm{GaP} / \mathrm{Si}$-структуры, осажденной на подложку $\mathrm{Si}(100)$ с разориентацией $4^{\circ}$ в направлении [110].
$500 \times 500$ нм $(512 \times 512$ точек $)$. Измерения среднеквадратичной шероховатости проводились в программном пакете Gwyddion.

\section{3. Результаты и обсуждение}

Изображение морфологии поверхности, полученное с помощью АCM для слоев $\mathrm{GaP}$, осажденных без плазменной обработки, представлено на рис. 1. Слои $\mathrm{GaP}$,

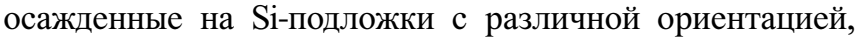
имеют очень гладкую поверхность. Значения среднеквадратичной шероховатости поверхности, приведенные в таблице, находятся на уровне 0.1 нм. Таким образом, на начальной стадии наблюдается двумерный рост $\mathrm{GaP}$ на поверхности $\mathrm{Si}$-подложек в независимости от их ориентации. Двумерный рост также подтверждается результатами просвечивающей электронной микроскопии для многослойной структуры $\mathrm{GaP} / \mathrm{Si}$, осажденной на $\mathrm{Si}(100)$ с разориентацией $4^{\circ}$, которые представлены на
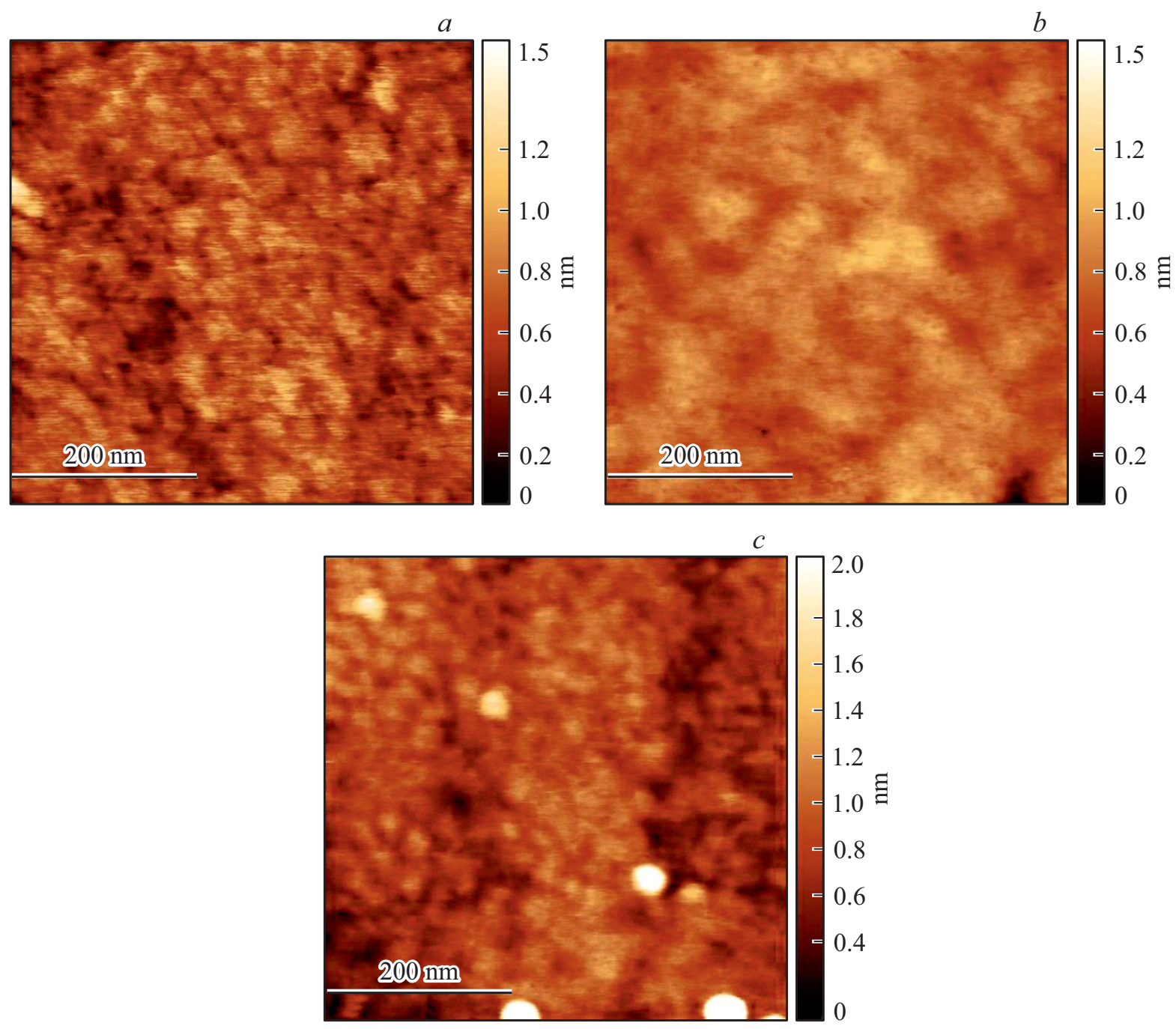

Рис. 3. Морфология поверхности слоя $\mathrm{GaP}$, осажденного с предварительной обработкой в плазме $\mathrm{H}_{2}$ на подложки $\mathrm{Si}$ с ориентацией: (100) с разориентацией $4^{\circ}$ в направлении [110] $(a) ;(100)(b) ;(111)(c)$. 

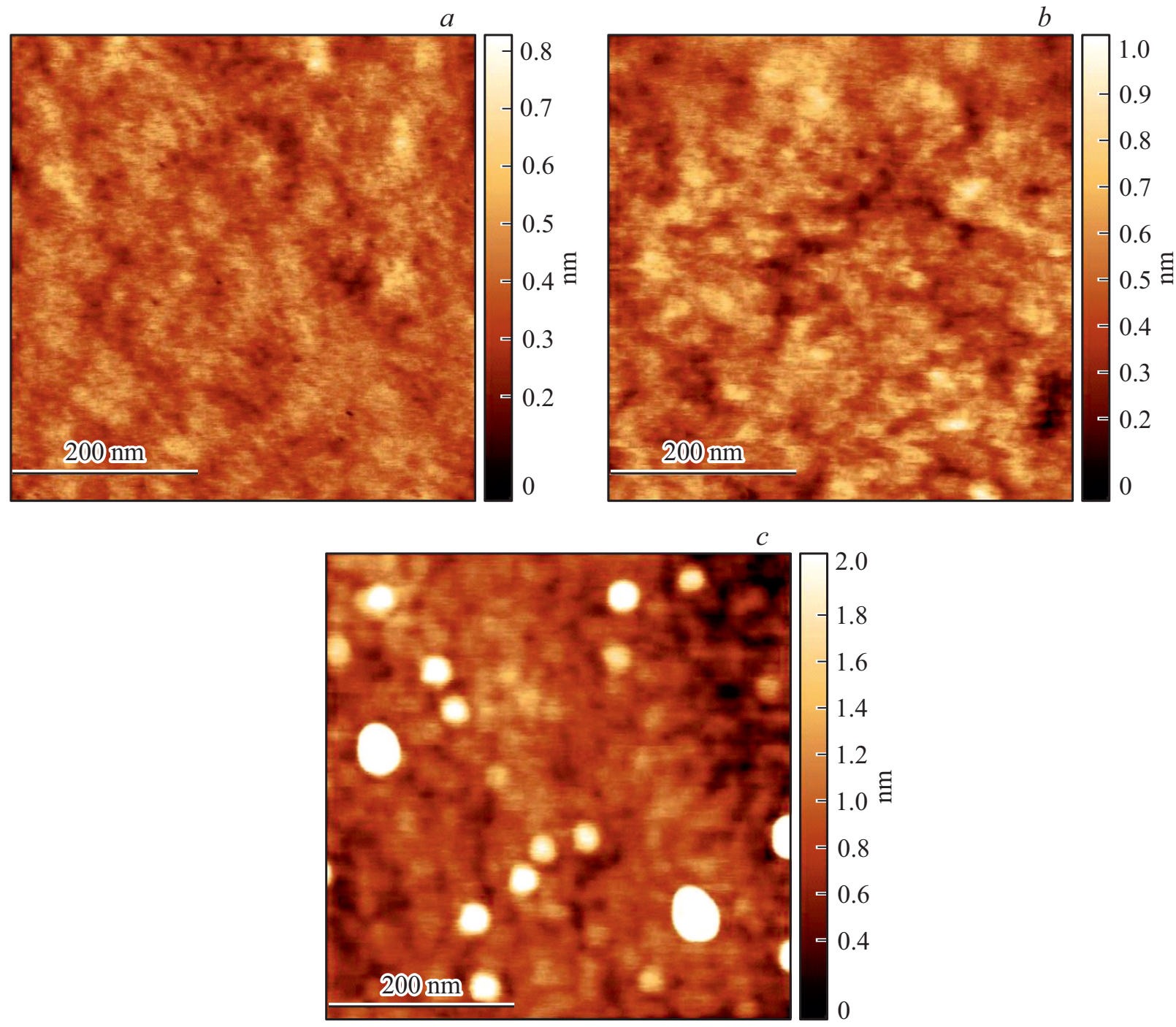

Рис. 4. Морфология поверхности слоя $\mathrm{GaP}$, осажденного с предварительной обработкой в плазме $\mathrm{Ar}$ на подложки $\mathrm{Si} \mathrm{c}$ ориентацией: (100) с разориентацией $4^{\circ}$ в направлении [110] (a), (100) (b), (111) (c).

рис. 2. Слой $\mathrm{GaP}$, осажденный на Si-подложку, наследует структуру подложки и имеет равномерно распределенную толщину 3 нм, т. е. на начальном этапе имеет место двумерный эпитаксиальный рост $\mathrm{GaP}$.

На следующем этапе проводилось исследование влияния обработки поверхности $\mathrm{Si}$ в плазме водорода. Морфология поверхности слоев $\mathrm{GaP}$, осажденных после обработки в водородной плазме, представлена на рис. 3. Видно, что шероховатость слоев $\mathrm{GaP}$, осажденных на подложки с ориентацией (100), возрастает в $1.2-1.5$ раза. Среднеквадратичное значение составляет 0.11 нм для точно ориентированной и 0.15 нм для вицинальной поверхности. В то время как для слоев $\mathrm{GaP}$, осажденных на подложку с ориентацией (111), шероховатость возрастает более существенно. На изображении АСМ (рис. 3,c) можно наблюдать формирование отдельных зерен размером 10-20нм, свидетельствующих об островковом механизме роста.
С одной стороны, предварительная предростовая обработка в водородной плазме часто используется для удаления оксидного слоя с поверхности подложек [16], что представляет большой практический интерес для разработки технологии, в которой может быть увеличено межоперационное время, за которое происходит окисление поверхности $\mathrm{Si}$ после обработки в растворе $\mathrm{HF}$. Дополнительная обработка в водородной плазме также использовалась в процессе циклического плазмохимического осаждения слоев $\mathrm{GaP}$ для удаления излишнего фосфора [10]. С другой стороны, известно, что обработка в водородной плазме может приводить к травлению кремния [17]. Наблюдаемое в данной работе ухудшение морфологии поверхности, наиболее вероятно, связано с эффектом травления $\mathrm{Si}$ в водородной плазме. Помимо этого, ранее было показано, что использование водородной плазмы повышенной мощности приводит к формированию дефектов в приповерхностной обла- 

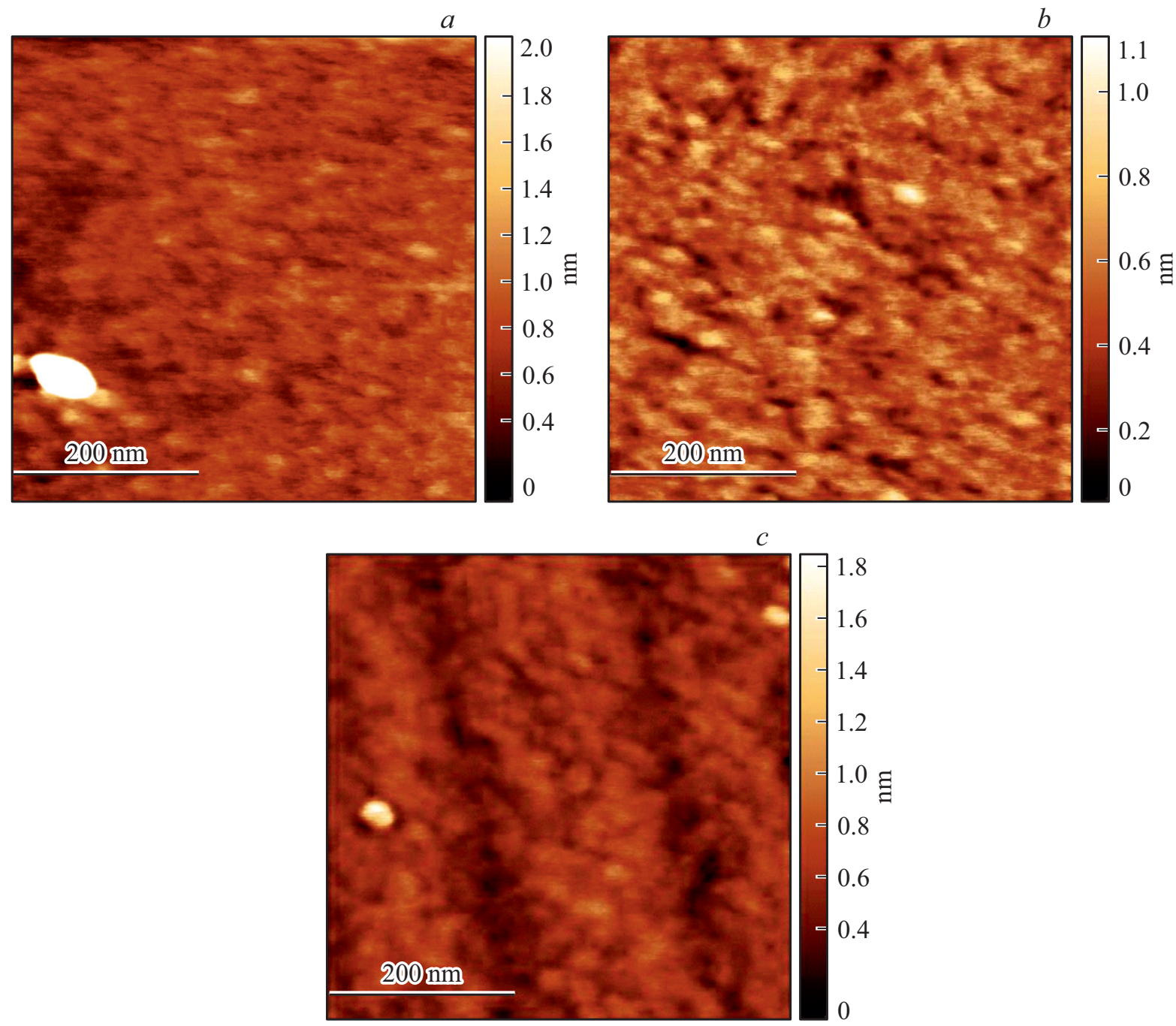

Рис. 5. Морфология поверхности слоя $\mathrm{GaP}$, осажденного после нанесения слоя $\mathrm{Si}$ на подложки с ориентацией: (100) c разориентацией $4^{\circ}$ в направлении $[110](a),(100)(b),(111)(c)$.

сти $\mathrm{Si}[11]$, ухудшающих фотоэлектрические свойства $\mathrm{GaP} / \mathrm{Si}$-гетероструктур. Таким образом, можно сделать вывод о негативном влиянии обработки Si-подложек в водородной плазме на морфологию поверхности растущих слоев $\mathrm{GaP}$.

Помимо обработки в водородной плазме, большой интерес представляет влияние воздействия плазмы Ar на поверхность растущей пленки $\mathrm{GaP}$, поскольку ее использование в режиме АCO позволяет достичь наилучших структурных свойств $\mathrm{GaP}$ [14]. Результаты измерения морфологии с помощью АСМ для слоев, осажденных после воздействия Ar-плазмы, представлены на рис. 4.

Для поверхности (100) как точно ориентированной, так и вицинальной, в отличие от водородной плазмы, плазма $\mathrm{Ar}$ не приводит к ухудшению морфологии поверхности GaP. В случае вицинальной поверхности наблюдается даже незначительное уменьшение среднеквадратичной шероховатости до 0.68 нм. Такой эффект может быть связан с локальным нагревом поверхно- сти $\mathrm{Si}$ непосредственно перед ростом $\mathrm{GaP}$, как было предположено в [18]. Наиболее значимым результатом является то, что воздействие плазмы $\mathrm{Ar}$ не приводит к травлению $\mathrm{Si}(100)$ и, следовательно, режим роста с использованием Ar-плазмы может применяться при формировании нуклеационных слоев для последующего эпитаксиального роста соединений $\mathrm{A}^{\mathrm{III}} \mathrm{B}^{\mathrm{V}}$ на кремнии. Для поверхности (111) воздействие Ar-плазмы приводит к эффекту, аналогичному водородной плазме. На поверхности видны зерна размером 20-30 нм, свидетельствующие о трехмерном росте GaP. Следует отметить, что для поверхности (111) воздействие плазмы $\mathrm{H}_{2}$ или $\mathrm{Ar}$ приводит к резкому изменению механизма роста с увеличением среднеквадратичной шероховатости в 2 раза.

Однако совершенно иная картина наблюдается при использовании предварительно осажденного эпитаксиального слоя $\mathrm{Si}$, как показано на рис. 5. В этом случае поверхность слоя $\mathrm{GaP}$, осажденного на $\mathrm{Si}$ (111), более 
гладкая по сравнению с обработкой в плазме $\mathrm{H}_{2}$ или Ar. Отсутствие зернистой структуры позволяет сделать заключение о двумерном росте $\mathrm{GaP}$. Для поверхности (100) картина полностью повторяет ситуацию с обработкой в водородной плазме. Во время роста эпитаксиального слоя $\mathrm{Si}$ используется очень сильное разбавление в водороде и, следовательно, поверхность Si-подложки дополнительно подвергается воздействию водородной плазмы, что объясняет полученный результат.

\section{4. Заключение}

Таким образом, проведенные исследования начальных условий роста показали, что наименьшая среднеквадратичная шероховатость поверхности растущих слоев $\mathrm{GaP}(<0.1 \mathrm{Hм})$ была достигнута для подложек (100) с разориентацией в $4^{\circ}$. Слои $\mathrm{GaP}$, выращенные на точно ориентированных (100) подложках обладали шероховатостью $\sim 0.1$ нм, а на подложках с ориентацией (111) 0.12 нм. Было обнаружено, что обработка поверхности $\mathrm{Si}$-подложек с ориентацией (100) в водородной плазме приводит к незначительному увеличению шероховатости поверхности растущих слоев $\mathrm{GaP}(0.12-0.14 \mathrm{Hм})$, что связывается с эффектом неоднородного травления кремния в водородной плазме. При обработке поверхности (100) кремния в плазме аргона шероховатость поверхности существенно не меняется по сравнению с химической обработкой поверхности. При использовании промежуточного эпитаксиального слоя $\mathrm{Si}$ морфология слоев $\mathrm{GaP}$ аналогична ситуации с применением водородной плазмы, что также связано с эффектом травления в водородной плазме по причине высокой концентрации водорода в процессе эпитаксиального роста кремния. Было показано, что на начальном этапе роста слоев $\mathrm{GaP}$ на Si-подложках, точно ориентированных (100) и с разориентацией, происходит двумерный рост как после химической, так и после плазменной обработки поверхности. При росте на подложках (111) после плазменной обработки поверхности наблюдается переход в трехмерный рост. За 20 циклов размер островков достигает $30-40$ нм.

\section{Финансирование работы}

Работа выполнена при финансовой поддержке за счет гранта РНФ № 17-19-01482 П.

\section{Конфликт интересов}

Авторы заявляют, что у них нет конфликта интересов.

\section{Список литературы}

[1] K. Yoshikawa, W. Yoshida, T. Irie, H. Kawasaki, K. Konishi, H. Ishibashi, T. Asatani, D. Adachi, M. Kanematsu, H. Uzu, K. Yamamoto. Sol. Energy Mater. Sol. Cells, 173, 37 (2017).
[2] J. Bullock, M. Hettick, J. Geissbühler, J. Alison, T. Allen, C. Sutter-Fella, T. Chen, H. Ota, E. Schaler, S. Wolf, C. Ballif, C. Cuevas, A. Javey. Nature Energy, 1, 15031 (2016). DOI: $10.1038 /$ nenergy.2015.31

[3] J. Cui, T. Allen, Y. Wan, J. Mckeon, C. Samundsett, D. Yan, X. Zhang, Y. Cui, Y. Chen, P. Verlinden, A. Cuevas. Sol. Energy Mater. Sol. Cells, 158, 115 (2016).

[4] X. Yang, P. Zheng, Q. Bi, K. Weber. Sol. Energy Mater. Sol. Cells, 150, 32 (2016).

[5] J. Geissbühler, J. Werner, S. Martin de Nicolas, L. Barraud, A. Hessler-Wyser, M. Despeisse, S. Nicolay, A. Tomasi, B. Niesen, S. De Wolf, C. Ballif. Appl. Phys. Lett., 107, 081601 (2015).

[6] H. Wagner, T. Ohrdes, A. Dastgheib-Shirazi, B. Puthen-Veettil, D. König, P.P. Altermatt. J. Appl. Phys., 115, 044508 (2014).

[7] I. Sakata, H. Kawanami. Appl. Phys. Express, 1, 091201 (2008).

[8] A.S. Gudovskikh, K.S. Zelentsov, A.I. Baranov, D.A. Kudryashov, I.A. Morozov, E.V. Nikitina, J.-P. Kleider. Energy Procedia, 102, 56 (2016).

[9] W.C. Cooley, R.J. Janda. Handbook of Space-Radiation Effects on Solar-Cell Power Systems (published by NASA, Washington, D.C., 1963).

[10] A.S. Gudovskikh, I.A. Morozov, A. V. Uvarov, D.A. Kudryashov, E.V. Nikitina, A.S. Bukatin, V.N. Nevedomskiy, J.-P. Kleider. J. Vac. Sci. Technol. A, 36, 021302 (2018).

[11] A.S. Gudovskikh, A.V. Uvarov, I.A. Morozov, A.I. Baranov, D.A. Kudryashov, K.S. Zelentsov, A. Jaffré, S. Le Gall, A. Darga, A. Brezard-Oudot, J.-P. Kleider. Phys. Status Solidi A, 216, 1800617 (2018).

[12] A.S. Gudovskikh, A.V. Uvarov, I.A. Morozov, A.I. Baranov, D.A. Kudryashov, E.V. Nikitina, J.-P. Kleider. Phys. Status Solidi C, 14, 1700150 (2017).

[13] A.S. Gudovskikh, A.V. Uvarov, I.A. Morozov, A.I. Baranov, D.A. Kudryashov, E.V. Nikitina, A.A. Bukatin, K.S. Zelentsov, I.S. Mukhin, A. Levtchenko, S. Le Gall, J.-P. Kleider. J. Renew. Sustain. Energy, 10, 021001 (2018).

[14] A.V. Uvarov, A.S. Gudovskikh, V.N. Nevedomskiy, A.I. Baranov, D.A. Kudryashov, I.A. Morozov. J. Phys. D: Appl. Phys., 53, 345105 (2020). DOI: 10.1088/1361-6463/ab8bfd

[15] A.S. Gudovskikh, A.V. Uvarov, I.A. Morozov, A.I. Baranov, D.A. Kudryashov, K.S. Zelentsov. Materials Today: Proceedings, 21, 47 (2020). DOI: 10.1016/j.matpr.2019.07.655.

[16] Y.B. Park, S.W. Rhee. Appl. Phys. Lett., 68, 2219 (1996). https://doi.org/10.1063/1.115864

[17] J. Geissbuhler, S. De Wolf, B. Demaurex, J.P. Seif, D.T.L. Alexander, L. Barraud, C. Ballif. Appl. Phys. Lett., 102, 231604 (2013).

[18] H.-Y. Shih, W.-H. Lee, W.-C. Kao, Y.-C. Chuang, R.-M. Lin, H.-C. Lin, M. Shiojiri, M.-J. Chen. Sci. Rep., 7, 39717 (2017).

Редактор Г.А. Оганесян 


\title{
Study of the Effect of Surface Treatment of Si Substrates on the Morphology of GaP Layers Obtained by Plasma-Enhanced Atomic Layer Deposition
}

\author{
A.V. Uvarov ${ }^{1}$, V.A. Sharov ${ }^{1,2}$, D.A. Kudryashov' ${ }^{1}$, \\ A.S. Gudovskikh ${ }^{1,3}$ \\ ${ }^{1}$ Alferov University, \\ 194021 St. Petersburg, Russia \\ 2 loffe institute, \\ 194021 St. Petersburg, Russia \\ ${ }^{3}$ St. Petersburg Electrotechnical University „LETI“, \\ 197376 St. Petersburg, Russia
}

\begin{abstract}
Research has been carried out on the atomic-layer deposition of $\mathrm{GaP}$ layers on $\mathrm{Si}$ substrates with different orientations and with different preliminary surface treatment. The deposition of $\mathrm{GaP}$ was carried out by the method of plasma-chemical atomiclayer deposition using in situ treatment in argon plasma. It is shown that at the initial stage of the growth of $\mathrm{GaP}$ layers on $\mathrm{Si}$ substrates precisely oriented (100) and with misorientation, two-dimensional growth occurs both after chemical and plasma surface treatment. Upon growth on (111) substrates, after plasma treatment of the surface, a transition to three-dimensional growth is observed at which the size of islands reaches $30-40 \mathrm{~nm}$. The smallest root-mean-square roughness of the surface of growing $\mathrm{GaP}$ layers (less than $0.1 \mathrm{~nm}$ ) was achieved for (100) substrates with a misorientation of $4^{\circ}$. $\mathrm{GaP}$ layers grown on exactly oriented (100) substrates had a roughness of about $0.1 \mathrm{~nm}$, and on substrates with (111) orientation $-0.12 \mathrm{~nm}$. It was found that the surface treatment of $\mathrm{Si}$ substrates with the (100) orientation in hydrogen plasma leads to a slight increase in the surface roughness of growing GaP layers $(0.12-0.14 \mathrm{~nm})$, which is associated with the effect of inhomogeneous etching of silicon in hydrogen plasma. When treating the (100) silicon surface in argon plasma, the surface roughness does not change significantly in comparison with chemical surface treatment. On the surface of substrates with preliminary deposition of an epitaxial Si layer $4 \mathrm{~nm}$ thick, the morphology of $\mathrm{GaP}$ layers is similar to the situation with the use of hydrogen plasma.
\end{abstract}

